\title{
How do mobile information services improve quality of life? The case of Japanese students
}

\section{Authors Information:}

1. Names of the authors:

(1) Qazi Mahdia Ghyas

(2) Fumiyo N. Kondo (corresponding author)

2. Affiliation of the authors

(1) \& (2), Department of Social Systems and Management, Graduate School of Systems\& Information Engineering, the University of Tsukuba, Ibaraki, Japan.

\section{Email address:}

(1) mahdia.ghyas@gmail.com

(2) kondo@sk.tsukuba.ac.jp; (corresponding author)

6. Address of the corresponding author:

1-1-1Tennoudai, Tsukuba-shi, Ibaraki 305-8573, Japan.

\section{Bibliography}

(1) Ghyas Qazi Mahdia is currently a PhD candidate in dept. of Social System And Management at the University of Tsukuba under the supervision of Professor Fumiyo N. Kondo. She has researched the need analysis on mobile services for Japan and USA users. Her other research work was the behavioral intention to use e-readers for Japan users based on Decomposed theory of planned Behavior. She has published proceedings in International Conference on Mobile Services, Resources and Users.

(2) Fumiyo N. Kondo is an Assistant Professor at University of Tsukuba, in Ibaraki. Her research interest is in mobile marketing and dynamic statistical analyses in marketing. She had worked for 10 years at A. C. Nielsen Company in Japan as an account executive and a statistical officer. 
Abstract: Every technology should be geared to improve the quality of users' lives. Our study aims to understand how mobile information services (MIS) contribute to quality of life (QoL) for young mobile users. This paper attempts to provide a comprehensive analysis of relationship between two variables: the contribution of MIS in fifteen specific life domains and the contribution of MIS to overall quality of life (QoL). We examined bottom-up spillover theory with original and our additional life domains. Eleven life domains derived from previous research include: leisure life, family life, friend life, cultural life, work life, community life, consumer life, financial life, health life, safety life, and self-life. Our proposed four life domains are: Home-Healthcare life, informational life, educational life and trustworthy life. Questionnaire surveys were conducted in Japan among young mobile users. We analyzed the data of 189 effective respondents. Results from this study clearly indicate that two variables (Individual Contribution and Overall Contribution) are valid and reliable to analyze. Contribution to the Informational life has the highest influence on the Overall Contribution for Japanese young, followed by culture life, friend life, leisure life, educational life and work life.

Keywords: Quality of life; life domains; contribution; bottom-up spillover theory; Young users; informational life; educational life; leisure life; cultural life; work life; friend life.

\section{Introduction}

Nicolas et al. (2008) defined mobile information service as advanced data services that have look and feel at internet pages and accessible via mobile phones at $3 \mathrm{G}+$ mobile communication networks. The consumers pay for their desired mobile contents or services. They may not pay additional fees for the access to excessive services. These services include mobile searches, news and sports information, music and video downloads, e-mail, instant messages, etc. Mobile information system is usually embedded in the user's life(Tamminen et al. 2004). The performance of a traditional information system (IS) is usually measured in terms of how effective it is at achieving specific need and goals (Gefen et al., 2003) or how satisfying it is to use for particular tasks (e.g., Bhattacherjee and Premkumar (2004). One of the goals of any technology should be to improve the quality of its users' lives (Straub and Watson, 2001). The needs and uses of mobile information services may differ on the basis of age. If there are any differences present in service needs between younger and older, mobile companies need to vary their international marketing strategies and tactics.

Prior studies of mobile computing have employed satisfaction (Choi et al. 2005) and intention to use (Yang, 2005) to investigate the impact of mobile computing technologies. These outcome variables measure users' feelings or attitudes at the time they use the system, rather than the impact of the system on their overall quality of life (QoL). Very few studies directly addressing the impact of IS on overall QoL.Rahman et al. (2005) presented a picture of conditions of the world with respect to such interrelated domains of QoL. Choi et al. (2007a) proposed eleven relationships between Individual Contribution and Overall Contribution of QoLin Korea and Japan and found some of them had stronger influence on the Overall Contribution.

There are also very few studies on how young people's QoL has been improved owing to the mobile technology. At present we have little sense of how much MIS affects young's QoL, 
because, as said, QoL has largely been ignored in mainstream IS literature. At present we do not even know into which domains of a young user's life effect has. Few studies have actually developed to analyze the relationship between technology and QoL. The main goal of this study is to construct a theoretical model that can reliably and validly measure the relationship between MIS and QoL. We designate "contribution to QoL" as an alternative outcome variable for MIS and examine through a consecutive empirical study in Japan, whether and how MIS contribute to young users' QoL.

Therefore, we examine the contribution of life domains to student's "QoL" after using MIS for Japan which has an expanding mobile market. We ground our research framework in the following two parts. First one is the bottom-up spillover theory (explained in section 3.3) by Choi et al. (2007a) with their eleven individual life domains contribution of MIS to QoL. These life domains are: leisure life, family life, friend life, cultural life, work life, community life, consumer life, financial life, health life, safety life, and self-life. Second, our newly proposedfour individual life domains contribution of MIS to QoL: Home-healthcare life, informational life, educational life and trustworthy life. These have conceptualized from previous studies (Choi et al. 2007b; Jing and Andy, 2010; and Nguyen et al. 2010). More details will be provided later.

The rest of the article is organized as follows. The next sections will describe the overview of QoL, individual life domains with new ones, bottom-up spillover theory, and contribution to QoL. These are followed by sections on methodology and statistical results. The last sections present a summary of the discussion, conclusions, implications and directions for future research.

\section{Mobile Information Services in Japan}

In Japan 2014, there were 137.9 million mobile subscribers which were $108 \%$ of total population. Among them 108.8 million was 3rd generation or 4th generation mobile subscribers which were $85.3 \%$ of total population (Telecommunications Carriers Association Japan, 2014). The smart phone market in Japan has expanded in 2010, sparked by the introduction of iPhone 4, innovative mobile services and massive TV commercials.Japanese advertising and PR firm, Hakuhodo surveyed internet users in Japan in June 2013 and found a smartphone penetration rate is higher among younger populations. More than three-quarters of internet users ages 15 to 19 owned a smartphone, as did more than seven out of 10 of those between 20 to 29 years old. The Japanese people who purchased a smartphone from April to September of 2013 are 82\%. (Mobile marketing Data Lab, Japan 2013).

Four factors of mobile services have identified by Ghyas et al., (2011): Information intensiveness (Factor 1), entertainment (Factor 2), low penetration service (Factor 3), and communication service (Factor 4) on Japan 2008 and 2009 data. Factor 1 refers to services that require a high degree of information, such as radio, the Internet, learning, health, infotainment content, stock trading, shopping services, coupon and advertising information services, online storage services, reservation or booking, and location-based services. Many Japanese people look at their mobile device as a central source of information gathering. This leads to a -Keitai (mobile phone) Culture that is more obvious in Japan than in other countries, partially because of the Japanese people's affection for technology in general. 
How do mobileinformation services improve quality of life? The case of Japanesestudents

Japanese adults and teenagers rely on their mobile phones for the types of functions that a laptop or desktop computer would normally provide.

\section{Theoretical Background}

\subsection{Quality of Life (QoL)}

The term QoL has been defined differently by various scholars. McCall (1975) defines QoL as 'necessary conditions for happiness', while Terhune (1973) defines it as subjective wellbeing.There are many terms that are used to represent well-being. Commonly used terms are QoL, standards of living, human well-being, and welfare. QoL is a measure of how happy people or how fulfilled they are in terms of their various wants and needs.

Studies of QoL have been conducted in diverse areas, including marketing (e.g. Sirgy, 1996, health (e.g. Leung et al. 2004), and education (e.g. Huebner and Gilman, 2002). However, only a few studies have been conducted in the area telecommunication services for young users. Here we will try to measure the contribution of mobile information services empirically and will provide a theoretical model that explicitly linked MIS and QoL for young users in Japan.

\subsection{Individual life domains}

QoL researchers have identified a number of distinct life domains that encompass the various places, things, activities, roles, and relationships in which a person typically finds himself or herself involved (Andrews and Withey, 1976). They propose that people actually experience and store the various events of their life in distinct domains, including leisure life, family life, friend life, cultural life, work life, community life, consumer life, financial life, health life, safety life, and self-life. These eleven life domains have been examined for mobile data services by Choi et al. (2007a) concerning Japan and Korea. Our newly added life domains are educational life (Andrews and Withey, 1976, Choi et al. 2007b), homehealthcare life (Jing and Andy, 2010), trustworthy life (Jing and Andy, 2010) and informational life (Nguyen et al., 2010) which are discussed below:

Informational life: Information communication technology and the Internet can offer benefits in addressing their information needs (Nguyen et al., 2010). Mobile phone with advanced technology may be a general source of information. With the availability of mobile devices, it becomes easy to gain access to the tremendous amounts of information on the Internet anywhere and anytime. So, here we will observe whether mobile information services may contribute to user's informational life to improve the quality of life.

Educational life: Word translation anytime anywhere, reading e-books via mobile, etc., can improve the learning and teaching activities of mobile users. Choi et al. (2007b) did not get significant effect between the contribution of mobile data services to educational life and the contribution to overall. According to Diener \& Smith (1999) small but significant correlations between education and subjective well-being have often been found. It is to be expected that mobile information services may affect the young people's educational life to improve their overall quality of lives. 
Trustworthy life: There are two main actors in trust: the trustor would be the consumer of mobile information services and the trustee which is the trusted party. In order to provide personalized services, mobile services provider may need to locate users' position and collect users' profiles. Users may feel threatened when the technology has the capability to track users' actions and store personal information outside the users' control. Trust can help reduce the uncertainties a user faces when using mobile services. Thus, here we will observe whether trustworthiness from mobile service provider, can improve the quality of life of users.

Home-healthcare life: Home-healthcare life is the activities pertaining to do some self medical care activities in home through using advanced mobile technology without going to a hospital, doctor or clinic. Users require special health vigilance, including monitoring of their physical conditions (e.g. blood pressure, etc.) and the fulfilment of some medication agenda. For example, there are some fitness applications in smartphone that are mainly designed for the young generation with the specific focus on weight loss and diet management.

We are interested in here to understand how MIS contributes to QoL than in how generally satisfied people are with their lives. As the use of the mobile phone blurred the boundary between home and work (Haddon, 1998), MIS can be used crossed time and place (Palen, 2002). Therefore, MIS has the potential to affect many life domains. Moreover, we did not know yet which domains were most relevant to MIS in different countries and different users. Therefore, our study has investigated the following life domains from Choi et al. (2007a), which have shown in Table 1.

\section{Table 1 Life Domains}

\subsection{Bottom-up spillover theory}

The bottom-up spillover theory (Andrews and Withey, 1976) is a model of the relationship between individual life domainsand quality of overall life. The theory indicates that QoL in individual domains has spillover effects on overall QoL. In other words, happiness insubordinate individual life domains can spill over to produce superordinate overall happiness (Andrews and Withey, 197 model. The premise of this model is that overall life satisfaction is functionally related to satisfaction within each of the individual life domains, which can be measured by satisfaction with specific events in each life domain (Sirgy, 2002).

\subsection{Contribution to QoL}

The basic premise of the bottom-up spillover theory is that satisfaction levels within individual life domains affect the overall level of life satisfaction (Sirgy, 2002). This relationship between Individual Contribution and Overall Contribution is displayed as our research model in Fig. 1. The bottom layer of our model represents the contribution of MIS to QoL in those domains (henceforth, Individual Contribution). The contribution of MIS to quality of individual life domains can be measured by the perceived contribution of specific use-experience of MIS services in that domain. The top layer in our model represents the specific contribution of MIS to overall QoL (henceforth, Overall Contribution). Like 
How do mobileinformation services improve quality of life? The case of Japanesestudents

Individual Contribution, Overall Contribution is conceptualized as the perceived contribution of MIS services to overall QoL.

Fig. 1. Relationship between individual contribution and overall contribution from Choi et al. (2007a)

Past studies suggest that IT does have an influence on users' QoL. For example, Heijden's (2004) study of adoption behavior for hedonic systems implies that IT may have effects on leisure or culture life. Bhattacherjee's (2001) account of users' continuance behavior in online banking systems implies that such systems affect QoL in the domain of financial life. Choi et al. (2007a) measured the contribution of a mobile data service (MDS) technology to the quality of users' lives. They have examined eleven individual life domains for Korean and Japanese respondents. Whereas, we will try to examine fifteen life domains with our proposed four life domains.

Our measures concern spillover of contribution to QoL by MIS. Therefore, contributions of MIS to QoL within individual domains should affect the contribution of MIS to overall QoL. With our proposed four new life domains is displayed as our research model in Fig. 2. We expect that improvement of QoL in each life domain (original and additional) after using MIS will positively influence overall QoL for young Japanese mobile users.

Source of life domains from 1-11: Choi et al. (2007) Figure 2. Relationship between individual contribution and overall contribution with proposed life domains

\section{Methodology}

\subsection{Data}

A survey was conducted in Japan of 245 mobile phone users at a university in Ibaraki. An online questionnaire was distributed. The Japanese survey was conducted in Ibaraki in February, 2013. We used responses from users who were 20-39 years for this research. Major respondents were young adults as it has been found that the mobile phone has become a key information technology for youth (de Chenecey, 2002). Our participants are the Japanese young users of mobile information services via mobile phone with internet convergence. For having internet in mobile phone, most of the users have smartphone. So, the sample in our research contains mostly smart phone users.We eliminated some responses which had missing values. Therefore, after the elimination, in Table 2 there were 189 respondents to do the analysis for Japan, 2013.

Questions measuring Individual Contribution in the fifteen life domains were based on the MIS use experiences. Our initial survey items for eleven original life domains were adapted from Choi et al. (2007a). The items of our additional four life domains were adopted from Andrews and Withey (1976); Jing and Andy (2010) and Nguyen et al. (2010). We chose to use the formative indicators elicited in order to reflect concrete use experiences with MIS because our theoretical foundation, the Bottom-up Spillover Theory, required highly specific events and experiences at the bottom of the satisfaction hierarchy model. Subjects were asked to rate how much they agree that each specific experience of using MIS contributes to 
the QoL in the corresponding individual life domains. We constructed questions measuring Overall Contribution of MIS to QoL as reflective indicators based on the Satisfaction with Life Scale (SWLS), which is one of the most widely used scales in QoL research, with high internal consistency and test-retest reliability(Pavot and Diener, 1993). We used the following sets of 7-point Likert scales: Strongly disagree/strongly agree for individual and overall contribution. The survey questions are shown in Appendix 1.

Table 2 Demographics of Respondents

\subsection{Analytical Method}

The validity and reliability of the measures were tested using Partial Least Squares (PLS), a method well suited to handle both formative indicators (for Individual Contribution) and reflective indicators (for Overall Contribution) (Chin, 1998). The research models were analyzed for Japan 2013 via PLS by using the statistical software smart-PLS version 2.0 M3. PLS also has been used to construct a theory of mobile data service contribution to QoL by Choi et al. (2007a) concerning Japanese and Korean mobile users.

\subsection{Validity and Reliability of the Measures}

There are two types of measurement scale in structural equation modeling, i.e., formative or reflective. In the research by Choi et al. (2007), both reflective and formative measurements were present in the same model. PLS is appropriate for handling both formative indicators and reflective indicators (Chin, 1998).

Because the criteria for assessing reflective and formative constructs are different, we assess the two types of constructs separately. In PLS, loadings represent the influence of individual scale items on reflective constructs (Bollen and Lennox, 1991).For reflective measurement scale, their indicator reliability, internal consistency reliability, or discriminant validity should be fully examined (Hair et al. 2013). Therefore, In order to assess the reliability and validity of the reflective constructs, we checked the factor loadings as confirmatory factor analysis, composite reliability (CR), Cronbach $\alpha$ coefficient and average variance extracted (AVE) for Overall Contribution in Table 3. The results indicate that all the measuring items secure convergent validity at the indicator level and construct level and the internal consistency.

Table 3 Reliability and validity of overall contribution

Regarding the formative construct, In PLS, weights represent the comparable influence on formative constructs (Bollen and Lennox, 1991).Thus, we examine the formative item's weights, multicollinearity and discriminant validity of the formative construct. In a formative measurement model, the problem of indicator collinearity may occur if the indicators are highly correlated to each other. We have generated VIF and Tolerance values for collinearity checking. The collinearity statistics as shown in Table 4, indicating that multicollinearity is not severe (Hair et al. 2013). For confirmatory factor analysis in Table 5, the measuring items for one formative construct have the same factor loadings. All the individual measuring items show a value 0.5 or above (Afthanorhan, 2013) at the significance level of $1 \%$ in our model. 
Thus, all the measuring items used in this study are valid to measure equivalent variables in an individual manner. We used the standard Bootstrapping procedure of 5000 samples recommended by Hair et al. (2013) to test convergent validity. The weights and $t$-statistics of all formative indicators in Table 5, found to bear significant relationships within the corresponding life domains. Moreover, the weights for each of the question items are positive, which indicates that measures of Individual Contribution also were found to have the appropriate level of convergent validity.

Table 4 Collinearity statistics of formative constructs

Table 5 Reliability and validity of individual contribution

We tested nomological validity of the model with and without our additional four life domains. We tested whether domain-specific contribution of MIS to QoL had a significant relationship with Overall Contribution of MIS to QoL. The coefficient of determination, $\mathrm{R}^{2}$ was 0.58 for model 2 , indicating acceptable fit in Table 6 . The fifteen individual life domains moderately explain $58 \%$ of the variance in overall contribution.

Meanwhile, predictive relevance is another aspect that can be explored for the inner model. The obtained Stone-Geisser's $\left(\mathbf{Q}^{\mathbf{2}}\right)$ value (i.e., cross-validated redundancy measures) for overall contribution was 0.42 for model 2 in Table 6 , which indicates large predictive relevance. Regarding the overall quality of the PLS structural model, we computed the value of the Goodness of Fit (GoF) (Tenenhaus et al. 2005), which is shown in Table 6.TheGoF, $\mathbf{Q}^{\mathbf{2}}$ and $\mathrm{R}^{2}$ values for model 2 are larger than those for model 1, resulting in our proposed model comparatively a better model. Therefore, our newly added four life domains in model 2 are useful to forecast overall life and Overall Contribution and Individual Contribution were found to have appropriate levels of reliability and validity for Japan.

Table 6 Model selection criteria for each model

\section{Contribution of MIS to QoL for Japan}

According to the theoretical model in Fig. 2, the Individual Contribution of MIS will influence the Overall Contribution of MIS. In other words, if people feel that MIS improves their QoL in individual domains, they will also believe that MIS improves their overall QoL. However, we do not know which of the fifteen life domains are more closely related to the overall QoL. In order to explore these issues, we conducted a PLS analysis using the Bootstrap method of 5000 samples that is recommended by Hair et al. (2013) and estimated the path coefficients between Individual Contribution and Overall Contribution in Table 7.

The results from Japan indicate that contributions to six individual life domains had significant impacts on the overall contribution of MIS. In other words, if MIS can contribute to the QoL in the six life domains, it will have a high possibility of improving the overall QoL of young Japanese respondents. Contribution to the Informational life has the highest influence on the Overall Contribution with $\beta=0.19 ; \mathrm{t}=2.97 ; \mathrm{p}<0.001$, followed by culture life $(\beta=0.149 ; \mathrm{t}=4.273 ; \mathrm{p}<0.001)$, friend life $(\beta=0.17 ; \mathrm{t}=2.70 ; \mathrm{p}<0.001)$, leisure life $(\beta=$ $0.15 ; \mathrm{t}=2.84 ; \mathrm{p}<0.001)$, educational life $(\beta=0.11 ; \mathrm{t}=2.34 ; \mathrm{p}<0.05)$ and work life $(\beta=0.10$; 
$\mathrm{t}=2.02 ; \mathrm{p}<0.05)$. As the $\mathrm{t}$-statistics, all these path coefficients are significant at the level of $5 \%$ or less.

Our result for Japan has some similarities with those from Choi et al. (2007) for Korea and Japan. Choi et al. (2007) measured the contribution of a mobile data service technology to the quality of users' lives. From our Japan results, contribution to the cultural and leisure life has the influence on the Overall Contribution. These results are the same as those were significant in Choi et al., (2007) for Japan also. As the country is the same, Japan, we got similar result probably due to same cultural and economy. We also have some similarities in case of non-significant results. Consumer life, health life and safety life were not the determinant of overall contribution in Choi et al. (2007) for both Japan and Korea, we also found the same for Japan 2012.

Our results for Japan have some differences compare to those from Choi et al. (2007a) for Korea and Japan. They got significant effect of financial life and self life to the overall contribution for Japan. But we get insignificant result on those. This may be possibly due to the characteristics of sample such as gender ratio. Another difference is on Friend life, which is significant in our result, but insignificant for Japan as well as Korea in those of Choi et al. (2007a). All of our respondents are students, so, friend life is a focus for them. The contribution to work life in Choi et al. (2007a) for Japan was found to be negatively related to the Overall Contribution but in our result, it is opposite, positively related. Our respondents in Japan were in their twenties, it is reasonable that work life as part-timers may be important for them. Those differences indicate the sample difference on gender, age, or job status and timing.

Out of our additional four life domains, informational and educational life domains become significant for Japan in our results. Since the respondents all are students, MIS has strong impact on their educational lives by searching dictionary, on-line translation, on-line education and etc. MIS also has strong impact on their informational life by searching news, weather, maps, personal information and etc. Our data was from 2013at the later adoption stage of $3 \mathrm{G} / 4 \mathrm{G}$ services, so that mobile device has become a key device for information gathering after the introduction of $3 \mathrm{G} / 4 \mathrm{G}$ services. It helps user to get information via mobile anytime and anywhere.

Table 7 Comparative analysis between Japan 2013and Japan-Korea from Choi et al. (2007) in terms of path coefficients

\section{Discussion}

This study has two layers (Bottom layer: Individual Contribution; top layer: Overall Contribution) to measure the contribution of mobile information services to users' QoL. Results from the two consecutive studies clearly indicate that two variables are valid and reliable in the bottom-up spillover theory. As users perceived a stronger contribution of MIS in specific life domains, they perceived a stronger contribution of MIS to their overall QoL. The Individual Contribution in cultural, leisure, informational, friend, educational and work domain had the greatest impact on the Overall Contribution among Japanese young users. Our demographic values for Japan have some differences from Choi et al. (2007a) concerning Korea and Japan. They had 89\% Korean respondents of age group below 30 years. On the other hand, they had 17\% Japanese respondents' age of below 30 years. We have $97 \%$ 
Japanese respondents who are below 30 years old. The age of our sample has similarities with their sample for Korea but different from their Japan sample. In their study, 55-56\% respondents were male for Korea and Japan. However, $72 \%$ of respondents in our study are male, so that our sample is skewed in gender. Demographic information about the effective participants is presented in Table 8. They conducted a large-scale online survey in 20052006 before the introduction of $3 G$ services with diverse mobile user groups who had different technological, educational and economic profiles. On the other hand, our online survey was conducted in 2013 among students in a university when mobile data services have adopted much and who have almost the same technological, educational and economic profiles. The difference of gender, age, time, and user group may affect our results compare to them.

Table 8 The comparison of sample differences with Choi et al. (2007a)

Cultural and leisure life domains are significant as these in Choi et al. (2007a) for Japan. They explained the strong effects of leisure and cultural life for the Japanese people by the higher national wealth (GNP and GDP) of Japan. People with greater monetary resources are more interested in their leisure and cultural life. Although our data set was for 2013 but we got similar result because of the stable economy of the same country, Japan.

Contribution of MIS to QoL in the Informational life-our newly added life domain; has the significant positive impact on overall contribution of MIS. According to the proposed theory by Wilson (2006), information seeking behavior is triggered from physiological, sociopsychological, and cognitive needs as perceived by the information user. Wilson (2006) especially stressed the importance of studying the users' information needs and that such needs are embedded in the user life world, the user him/herself, his/her role (e.g. job tasks, care needs) and the environment. The information users in Japan may seek information from different sources. Mobile device is one of the greatest devices among choices to get information and Japanese young people can improve their life by getting information anytime anywhere through mobile devices.

Contribution of MIS to QoL in the friend life has significant positive impact on overall contribution of MIS. Relationship with friends should be considered in any measure of QOL (Rahman et al. 2005). Satisfaction with friend life is an important element of an individual's well-being in fact when they are young adults. It is quite reasonable that, in most cases, an individual young mobile user with strong friend ties will be happier by sending photos, contacting with friends and congratulating friends on their birthday, etc.

Contribution of MIS to QoL in the educational domain has significant effect on overall Contribution of MIS to QoL for Japan. But Choi et al. (2007b) did not get significant effect between the contribution of MDS to educational life and the contribution to overall for Korean young users. They showed the reasons were poor usability of mobile devices inhibits active participation, and their limited bandwidth precludes effective use of multimedia broadcasting on online education. Our data set was for Japan, 2013, when around 82\% of cell phones users were smart phone users. So, mobile devices become effective media or online education of young students. Hence, our result for educational life domain may become significant.

Contribution of MIS to QoL in work life has significant positive impact on overall contribution of MIS in our result. Rahman et al. (2005) identified the work life domains of depending on 
what were considered to be the major element of well-being. Estimates of unemployment rate and combined first, second and third level school gross enrolment ratio are used to capture the 'extent of work and productive activity' that exists in a country. Young citizens of Japan are productively engaged either in work employment, or engaged in the process of learning in school.

\section{Implications}

The study has several implications. First, it was noted that six significant individual life domains, specifically relevant to mobile computing environments that contribute in multiple ways to various facets of a young user's life. We recommend focusing on these life domains for young mobile users. Second, it verifies the reliability and the convergent, divergent, and nomological validity of the original and our newly proposed life domains and through an empirical study. These life domains can be used in future studies to measure MIS contribution to QoL.

This study firstly provides a framework to understand the contribution of MIS to young's quality of lives from the perspective of its actual user. The life domains proposed and verified in our study can be used in future studies, to evaluate the potential of MIS to contribute to young user's QoL. If a firm intends to specialize in a specific life domain for young users, our findings on contribution of MIS to QoL can indicate what services will be used, with what goals, in what contexts, and can thus suggest which services will most improve QoL for their users. The results on the relationship between Domain- Specific Contribution of MIS to QoL and Overall Contribution of MIS to QoL will also help companies allocate resources to the life domains that bear most strongly on overall QoL.

\section{Limitations}

Our study has some limitations. All of the respondents are young students who have good education and knowledge in technology who had from a national university in Japan. Also, they are convenience samples. Thus the results cannot be generalized to the whole population in Japan. Moreover, our respondents in Japan were clustered on males in their twenties which might bias the survey results. Second, this study was conducted in Japan with Japanese MIS users, and it is not clear whether the results can be applied to other countries. We recommend an increased focus on the importance of age, gender, culture and economic characteristics in future research.

\section{Conclusion}

This paper operationalized fifteen life domains with our newly added four life domains to measure the contribution of MIS to QOL across Japanese young students. We successfully applied bottom-up spillover theory for the use of MIS by Japanese young users and found the importance of information and educational life domains out of our proposed four life domains. By using a model to measure the contributions of mobile information services to QoL with the original and our additional life domains, the research of Choi et al. (2007a) and this research gave stable results after considering time difference. Out of these considered life domains of the QOL, we showed that the perceived contribution of each use experience 
for the following six life domains were found to be the key domains for Japanese young MIS users: informational life, cultural life, friend life, leisure life, educational life and work life. Our research also identified the importance of appropriateness of sample characteristics such as gender, age, and culture/economy. A technology used in as many contexts as MIS can enhance its users' lives in numerous ways. To assess those contributions, however, we need to know how they focused on specific tasks and functions for different user segments. Our study takes a step in that direction by offering a practical basis for measuring the contributions of mobile information services to QoL for young MIS users.

\section{Acknowledgement}

This work was supported by Grants-in-Aid for Scientific Research, No.25245054, from the Ministry of Education of the Japanese government.

\section{References}

C López-Nicolás C. L., Castillo M. F. and Bouwman H. (2008), An assessment of advanced mobile services acceptance: Contributions from TAM and diffusion theory models, Information \& Management 45 (6), 359-364.

Tamminen, S., Oulasvirta, A., Toiskallio, K., and Kankainen, A. (2004). Understanding mobile contexts. Personal and Ubiquitous Computing, 8: 135-143.

Gefen, D., Karahanna, E., and Straub, D. W. (2003). Trust and TAM in online shopping: An integrated model. MIS Quarterly, 27: 51-90.

Bhattacherjee, A., and Premkumar, G. (2004). Understanding changes in belief and attitude toward information technology usage: A theoretical model and longitudinal test. MIS Quarterly, 28, 2: 229-254.

Straub, D. W. and R. T. Watson (2001) "Research Commentary: Transformational Issues in Researching IS and Net-Enabled Organizations," Information Systems Research (12) 4, pp. 337345.

Choi, M. S., H. Choi , Y. C. Kim, and J. Kim (2005) "An Empirical Study on Post-adoption Behavior of mobile data Servicewith a focus on Comparison between services," Korean Marketing Review (20) 1, pp. 1-27.

Yang, K. C. C. (2005) "Exploring factors affecting the adoption of mobile commerce in Singapore," Telematics and Informatics (22) 3, pp. 257-277.

Choi, H., Kim, J., Lee, M., Gaglis, G., Naruse, K.,Constantious, I., Fife, E., andMayhew E. G. (2007a). Contribution to QoL: cross-national validation of new metrics for mobile data service technology in Korea and Japan, International Journal of Innovation and Technology Management Vol. 4, No. 2 (2007) 191-208

Choi H., Im, S. K., Lee, M., \&Kim,J. (2007b). Contribution to QoL: A New Outcome Variable for Mobile Data Service,Journal of the Association of Information System, Volume 8, Issue 12, Article 1, pp. 598-618, December 2007.

Rahman, T., Ron, C., M., andWandschneider, P. (2005).Measuring the QoL across Countries: A Sensitivity Analysis of Well-being Indices, UNU-WIDERWIDER Research Paper, World Institute for Development Economics Research, Volume:2005/06.

Jing, G., and Andy, K. (2010). "Mobile Application Development for Senior Citizens" (2010).PACIS 2010 Proceedings. Paper 214-223.

Nguyen, L., Evans, S., Wilde, W. D., and Shanks, G. (2010) "SupportingInformation Needs of Senior Citizens in Community Aged Care" (2010).ACIS 2010 Proceedings.Paper 7. 
How do mobileinformation services improve quality of life? The case of Japanesestudents

Diener, E. D., Suh, E. M., Lucas. E. E. Smith, H. L., (1999). Subjective Well-being: Three Decades of Progress. Psychological Bulletin. 125 (2). 276-302.

Hair, J. F., Hult, G. T. M., Ringle, C. M., andSarstedt, M. (2013). A Primer on Partial Least Squares

Structural Equation Modeling (PLS-SEM). Thousand Oaks: Sage.

McCall, S. (1975). 'QoL'. Social Indicators Research, 16: 299-349.

Terhune, K. W. (1973). 'Probing Policy Relevant Questions on the QoL', in: The Quality of

Life Concept. Washington, DC: Environmental Protection Agency.

Sirgy, M. J. (1996). Strategic marketing planning guided by the Quality-of-Life (QoL) concept. Journal of Business Ethics, 15: 241-259.

Leung, K. L., Kwok, S. P., Lam, S. C., Lee, J. F., Yiu, R. Y., Ng, S. S., Lai, P. B., and Lau, W. Y. (2004). Laparoscopic resection of recto sigmoid carcinoma: Prospective randomized trial. Lancet, 363: 2224-2229.

Huebner, E. S., and Gilman, R. (2002). An introduction to the multidimensional students'life satisfaction scale. Social Indicators Research, 60: 115-122.

Andrews, F. M., and Withey, S. B. (1976). Social Indicators of Well-Being: America's Perception of Life, Plenum Press, New York.

Haddon, L. (1998). Il ControllodellaComunicazione. Imposizione di Limitiall'usodelTelefono, (ed.)

L. Fortunati, Telecomunicando in Europa, Franco Angeli, Milano.

Palen, L. (2002). Mobile telephony in a connected life. Communications of the ACM, 45, 3: 78-82.

Sirgy, M. J. (2002). The Psychology of QoL, Kluwer, Dordrecht.

Heijden, V. D.,(2004). "User Acceptance of Hedonic Information Systems," MIS Quarterly, (28: 4).

Bhattacherjee, A. (2001) "Understanding Information Systems Continuance: An Expectation-

Confirmation Model," MIS Quarterly (25) 3, pp. 351-370.

deChenecey, S. P. (2002). Putting brands in their place, Young Consumers, 4(2), 47-50.

Pavot, W. and E. Diener. (1993) "Review of the Satisfaction with Life Scale," Psychological

Assessment (5) 2, pp. 164-171.

Chin, W. W. (1998). The Partial Least Squares Approach to Structural Equation Modeling,(ed) G. A.

Marcoulides, Modern Methods for Business Research.

Bagozzi, R. P., and Yi, Y. (2011). Specification, evaluation, and interpretation of structural equation models. Journal of the Academy of Marketing Science, 40, 8-34.

Wilson, T. D. (2006). "On user studies and information needs." Journal of Documentation, 62(6): 658 -670 .

Tenenhaus, M., Vinzi, V. E. Chatelin, Y. M., and Lauro, C. (2005). “PLS Path Modeling,” Computational Statistics and DataAnalysis (48:1), pp. 159-205.

Bollen, K. A., and Lennox R. (1991) "Conventional Wisdom on Measurement: A Structural Equation Perspective,"Psychological Bulletin (110) 2, pp. 305-314.

Telecommunications Carriers Association Japan, 2014).

http://www.tca.or.jp/english/database/2010/02/index.html

http://www.emarketer.com/Article/Smartphone-Use-Japan-Makes-Steady

Gains/1010226\#sthash.13vgEb5g.dpuf

https://mmdlabo.jp/investigation/detail_1243.html

Ghyas, Q. M., Kondo, N. F., \& Kawamoto, T. (2011). Communication needs of Japan and the United States: A comparative analysis of the use of mobile information services. Proceedings of the First International Conference on Mobile Services, Resources, and Users, Barcelona, Spain.

Table 1 Life Domains

\begin{tabular}{|l|l|}
\hline Life Domains & Defining Activities, Circumstances, Events \\
\hline Cultural & Activities and relationships with cultural richness \\
\hline
\end{tabular}


How do mobileinformation services improve quality of life? The case of Japanesestudents

\begin{tabular}{|l|l|}
\hline Leisure & Non-working activities, spare time activities, recreation \\
\hline Educational & Learning and teaching activities \\
\hline Consumer & $\begin{array}{l}\text { Purchase, preparation, consumption,possession, maintenance } \\
\text { and disposition activities of goods and services }\end{array}$ \\
\hline Financial & Activities for pay and revenues \\
\hline Health & Activities pertaining to mental and physical health \\
\hline Safety & Activities for personal safety \\
\hline Family & Activities with parents, children, and home \\
\hline Friend & Activities with colleagues and friends \\
\hline Self & Activities for self-representation and self-efficacy \\
\hline Community & Activities with on-line community \\
\hline $\begin{array}{l}\text { Health } \\
\text { Monitoring }\end{array}$ & Activities to monitor own health care \\
\hline Trustworthy & Activities of privacy and trustworthy \\
\hline Informational & Activities to get information \\
\hline Work & Mental and physical activities required by jobs and task \\
\hline
\end{tabular}

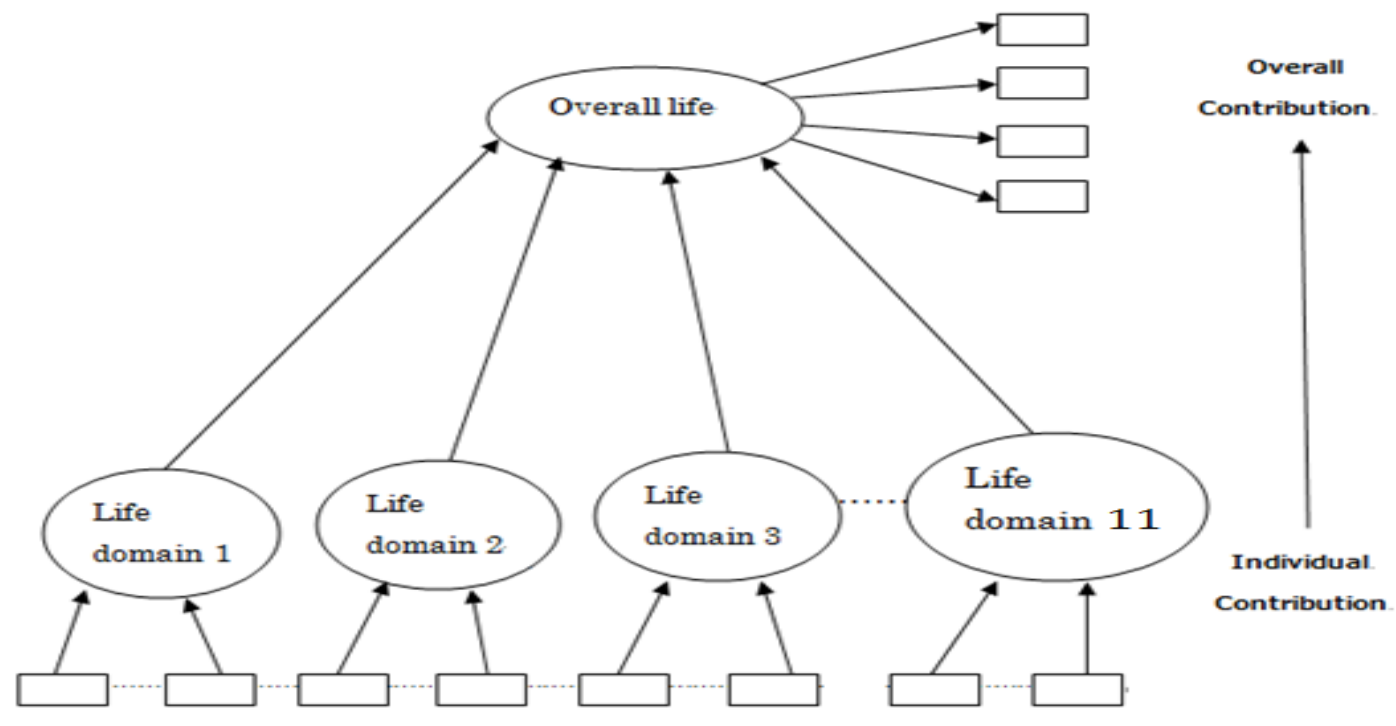

Fig. 1. Relationship between individual contribution and overall contribution from Choi et al. (2007a) 


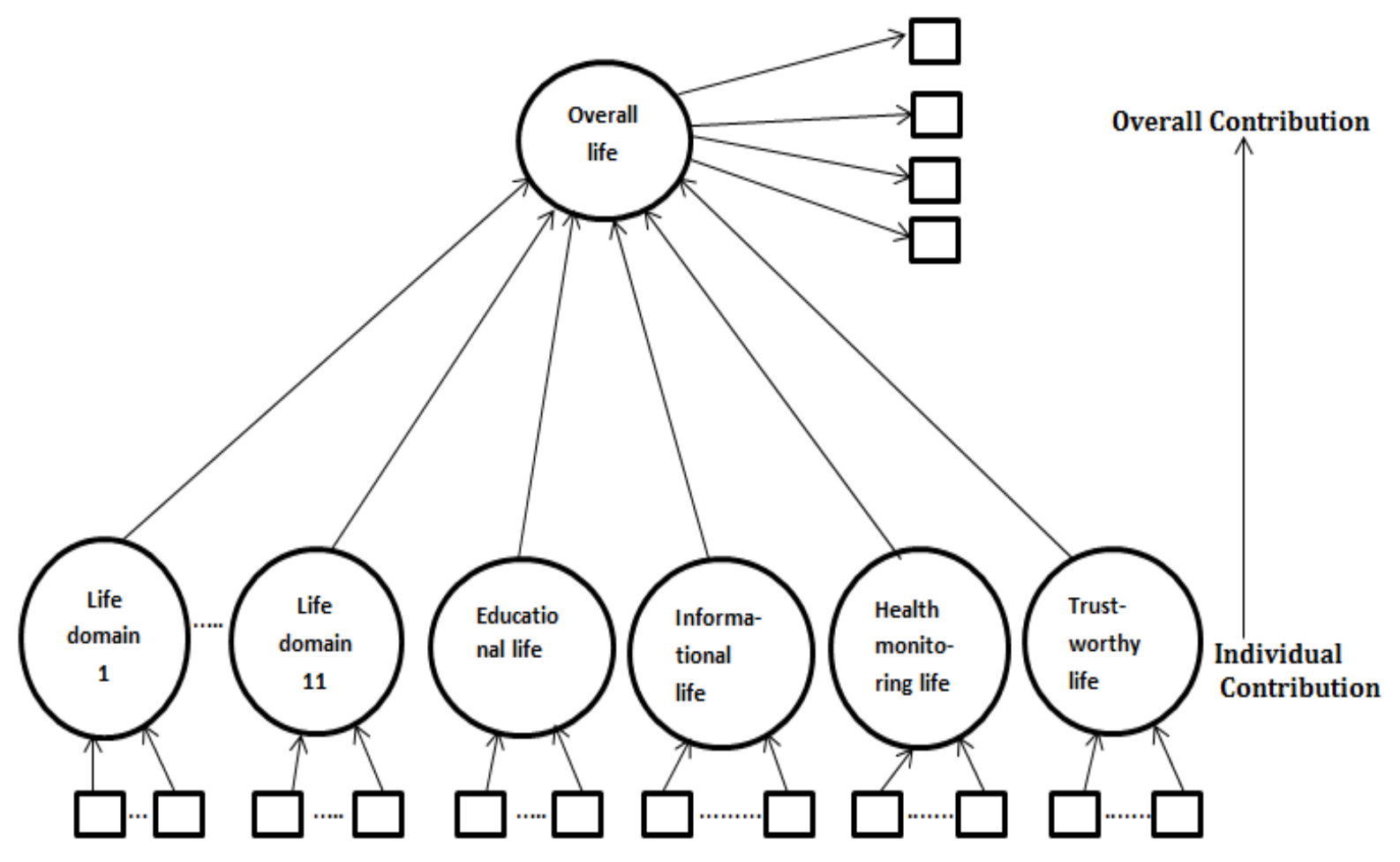

Fig. 2. Relationship between individual contribution and overall contribution with our proposed life domains

Table 2. Demographics of Respondents

\begin{tabular}{|l|l|r|r|}
\hline Category & Values & $\begin{array}{c}\text { Japan } \\
2013\end{array}$ & In $\%$ \\
\hline Gender & Male & 137 & $72 \%$ \\
\hline & Female & 52 & $28 \%$ \\
\hline Age & 19 years old or younger & 32 & $17 \%$ \\
\hline & $20-29$ years old & 151 & $80 \%$ \\
\hline & $30-39$ years old & 6 & $3 \%$ \\
\hline
\end{tabular}

Table 3. Reliability and validity of overall contribution

\begin{tabular}{|c|c|c|c|c|c|c|}
\hline $\begin{array}{l}\text { Reflective } \\
\text { Indicator }\end{array}$ & Items & $\mathrm{CR} \geq 0.70$ & AVE $\geq 0.50$ & Cronbach $\alpha \geq 0.70$ & Loading $\geq 0.50$ & $\begin{array}{l}\text { t-value at } \\
p<0.01\end{array}$ \\
\hline $\begin{array}{l}\text { Overall } \\
\text { Contribution }\end{array}$ & OVR 1 & 0.93 & 0.78 & 0.90 & 0.91 & 90.18 \\
\hline & OVR 2 & & & & 0.93 & 108.74 \\
\hline & OVR 3 & & & & 0.93 & 108.73 \\
\hline & OVR 4 & & & & 0.75 & 25.27 \\
\hline
\end{tabular}


Table 4. Collinearity statistics of formative constructs

\begin{tabular}{|l|r|r|}
\hline \multirow{2}{*}{ Independent Variables } & \multicolumn{2}{|c|}{ Collinearity Statistics } \\
\cline { 2 - 3 } & Tolerance $>0.20$ & VIF $<5$ \\
\hline Community Life & 0.552 & 1.810 \\
\hline Consumer Life & 0.449 & 2.228 \\
\hline Cultural Life & 0.524 & 1.909 \\
\hline Educational Life & 0.453 & 2.207 \\
\hline Family Life & 0.516 & 1.939 \\
\hline Financial Life & 0.546 & 1.832 \\
\hline Friend Life & 0.470 & 2.127 \\
\hline Health Life & 0.475 & 2.103 \\
\hline Home-Healthcare Life & 0.480 & 2.083 \\
\hline Informational Life & 0.363 & 2.757 \\
\hline Leisure Life & 0.385 & 2.597 \\
\hline Safety Life & 0.405 & 2.467 \\
\hline Self Life & 0.537 & 1.864 \\
\hline Trustworthy Life & 0.389 & 2.567 \\
\hline Work Life & 0.455 & 2.196 \\
\hline
\end{tabular}

Note: Dependent Variable: Overall contribution

Table 5. Reliability and validity of individual contribution

\begin{tabular}{|l|l|r|r|r|r|r|}
\hline Formative Indicators & Items & \multicolumn{1}{l|}{ CR $\geq 0.70$} & Weight & t-value & Factor Loadings $\geq 0.50$ & \multicolumn{1}{l|}{ t-value } \\
\hline & HEL 1 & 0.87 & 0.17 & 1.48 & 0.68 & 7.75 \\
\hline & HEL 2 & & 0.64 & 5.14 & 0.94 & 23.09 \\
\hline & HEL 3 & & 0.36 & 2.53 & 0.81 & 11.06 \\
\hline Home-Healthcare Life & HML 1 & 0.92 & 0.04 & 0.23 & 0.63 & 5.91 \\
\hline & HML 2 & & 0.98 & 9.57 & 0.99 & 79.28 \\
\hline Work Life & WOR 1 & 0.86 & 0.56 & 5.72 & 0.87 & 16.77 \\
\hline & WOR 2 & & 0.12 & 1.47 & 0.67 & 11.2 \\
\hline & WOR 3 & & 0.51 & 4.69 & 0.84 & 13.96 \\
\hline Safety Life & SAF 1 & 0.83 & 0.67 & 6.68 & 0.94 & 27.34 \\
\hline & SAF 2 & & 0.26 & 2.61 & 0.79 & 13.3 \\
\hline & SAF 3 & & 0.28 & 3.37 & 0.58 & 7.65 \\
\hline Financial Life & FIN 1 & 0.91 & 0.28 & 1.98 & 0.79 & 12.27 \\
\hline & FIN 2 & & 0.19 & 1.18 & 0.8 & 11.17 \\
\hline & FIN 3 & & 0.44 & 3.43 & 0.8 & 11.6 \\
\hline & FIN 4 & & 0.34 & 2.18 & 0.82 & 12.92 \\
\hline CSR 1 & 0.87 & 0.14 & 1.23 & 0.72 & 8.76 \\
\hline & CSR 2 & & 0.32 & 2.85 & 0.8 & 12.38 \\
\hline & CSR 3 & & 0.63 & 5.37 & 0.94 & 26.15 \\
\hline & CSR 4 & & 0.1 & 1.08 & 0.56 & 6.97 \\
\hline & FAM 1 & 0.87 & 0.34 & 3.06 & 0.74 & 10.63 \\
\hline Famsumer Life & FAM 2 & & 0.31 & 2.41 & 0.81 & 13.12 \\
\hline & FAM 3 & & 0.46 & 3.64 & 0.82 & 14.61 \\
\hline & FAM 4 & & 0.15 & 0.97 & 0.76 & 10.44 \\
\hline
\end{tabular}


How do mobileinformation services improve quality of life? The case of Japanesestudents

\begin{tabular}{|l|l|r|r|r|r|r|}
\hline & CUL 1 & 0.92 & 0.49 & 3.79 & 0.83 & 14.33 \\
\hline & CUL 2 & & 0.35 & 2.58 & 0.87 & 20.02 \\
\hline & CUL 3 & & 0.06 & 0.55 & 0.9 & 23.88 \\
\hline & CUL 4 & & 0.08 & 0.47 & 0.75 & 13.78 \\
\hline & CUL 4 & & 0.19 & 1.9 & 0.73 & 12.56 \\
\hline Friend Life & FRI 1 & 0.9 & 0.19 & 1.7 & 0.76 & 12.93 \\
\hline & FRI 2 & & 0.69 & 6.05 & 0.97 & 42.36 \\
\hline & FRI 3 & & 0.24 & 2.12 & 0.79 & 12.6 \\
\hline Community Life & COML 1 & 0.94 & 0.57 & 4.04 & 0.95 & 29.68 \\
\hline & COML 2 & & 0.5 & 3.53 & 0.93 & 24.54 \\
\hline Self Life & SEL 1 & 0.84 & 0.95 & 16.25 & 0.99 & 66.48 \\
\hline & SEL 2 & & 0.12 & 1.02 & 0.48 & 4.19 \\
\hline Informational Life & IL 1 & 0.86 & 0.52 & 5.28 & 0.87 & 19.41 \\
\hline & IL 2 & & 0.57 & 5.49 & 0.59 & 9.23 \\
\hline & IL 3 & & 0.06 & 0.78 & 0.9 & 21.41 \\
\hline Trustworthy Life & TWL 1 & 0.86 & 0.81 & 8.75 & 0.98 & 45.16 \\
\hline & TWL 2 & & 0.08 & 0.88 & 0.72 & 9.16 \\
\hline & TWL 3 & & 0.23 & 1.91 & 0.61 & 7.95 \\
\hline Educational Life & EL 1 & 0.89 & 0.5 & 5.85 & 0.89 & 23.54 \\
\hline & EL 2 & & 0.38 & 3.62 & 0.85 & 21.2 \\
\hline & EL 3 & & 0.29 & 2.56 & 0.8 & 13.65 \\
\hline Leisure Life & LSRL 1 & 0.91 & 0.39 & 3.7 & 0.86 & 18.93 \\
\hline & LSRL 2 & & 0.45 & 4.57 & 0.87 & 22.26 \\
\hline & LSRL 3 & & 0.31 & 3.17 & 0.88 & 26.83 \\
\hline
\end{tabular}

Table 6. Model selection criteria for each model

\begin{tabular}{|l|l|c|c|}
\hline \multicolumn{1}{|c|}{ Model Selection Criteria } & $\mathrm{R}^{2}$ of endogenous construct & $\mathrm{Q}^{2}$ & GoF \\
\hline Model 1 from Choi et al. (2007a) (Figure 1) & 0.54 & 0.40 & 0.65 \\
\hline Model 2 with our additional four life domains (Figure 2) & 0.58 & 0.42 & 0.67 \\
\hline
\end{tabular}

Table 7. Comparative analysis between Japan 2013 and Japan-Korea from Choi et al. (2007) in terms of path coefficients

\begin{tabular}{|l|r|r|r|r|r|l|}
\hline Hypotheses & $\begin{array}{c}\text { Japan } \\
2013\end{array}$ & t-value & $\begin{array}{c}\text { Japan } \\
\text { (Choi et al. } \\
\text { 2007a) }\end{array}$ & t-value & $\begin{array}{c}\text { Korea } \\
\text { (Choi et } \\
\text { al. 2007a) }\end{array}$ & t-value \\
\hline Cultural Life --> Overall Life & 0.18 & $4.08^{* * *}$ & 0.12 & $3.85^{* * *}$ & 0.02 & 0.27 \\
\hline Leisure Life--> Overall Life & 0.15 & $2.84^{* * *}$ & 0.11 & $3.39^{* * *}$ & 0.06 & 1.63 \\
\hline Community Life --> Overall life & 0.08 & 1.78 & 0.08 & 2.13 & 0.15 & $4.27^{* * *}$ \\
\hline Consumer Life --> Overall Life & 0.07 & 1.32 & 0.09 & 2.05 & 0.05 & 1.52 \\
\hline
\end{tabular}


How do mobileinformation services improve quality of life? The case of Japanesestudents

\begin{tabular}{|l|r|l|r|l|r|l|}
\hline Family Life --> Overall Life & -0.08 & 1.66 & 0.02 & 0.94 & 0.14 & $3.20^{* * *}$ \\
\hline Health Life --> Overall Life & 0.10 & 1.68 & -0.00 & 0.31 & 0.00 & 0.03 \\
\hline Safety Life --> Overall Life & -0.01 & 0.22 & 0.02 & 0.55 & 0.02 & 0.67 \\
\hline Self Life --> Overall Life & -0.08 & 1.65 & 0.37 & $10.84^{* * *}$ & 0.33 & $9.34^{* * *}$ \\
\hline Financial Life --> Overall Life & 0.00 & 0.09 & 0.23 & $6.34^{* * *}$ & 0.14 & $3.87^{* * *}$ \\
\hline Friend Life --> Overall Life & 0.17 & $2.70^{* * *}$ & 0.03 & 0.78 & 0.06 & 1.57 \\
\hline Work Life --> Overall Life & 0.10 & $2.02^{* *}$ & -0.06 & $2.52^{* * *}$ & 0.04 & 1.21 \\
\hline Home-Healthcare Life --> Overall Life & 0.09 & 1.64 & - & - & - & - \\
\hline Educational Life --> Overall Life & 0.11 & $2.34^{* *}$ & - & - & - & - \\
\hline Informational Life --> Overall Life & 0.19 & $2.97^{* * *}$ & - & - & - & - \\
\hline Trustworthy Life --> Overall Life & -0.02 & 0.45 & - & - & - & - \\
\hline $\mathrm{R}^{2}$ value & 0.58 & & 0.63 & & 0.51 & \\
\hline
\end{tabular}

Note: ${ }^{* *} p<0.001 ;{ }^{* *} p<0.05$

Table 8. The comparison of sample differences with Choi et al. (2007a)

\begin{tabular}{|l|l|r|r|r|r|r|r|}
\hline Category & Values & $\begin{array}{l}\text { Japan } \\
2013\end{array}$ & In $\%$ & $\begin{array}{l}\text { Korea (Choi et al. } \\
\text { 2007a) }\end{array}$ & In \% & $\begin{array}{l}\text { Japan (Choi et al. } \\
\text { 2007a) }\end{array}$ & In $\%$ \\
\hline Gender & Male & 137 & $72 \%$ & 507 & $56 \%$ & 569 & $55 \%$ \\
\hline & Female & 52 & $28 \%$ & 397 & $44 \%$ & 469 & $45 \%$ \\
\hline Age & 19 years old or younger & 32 & $17 \%$ & 177 & $20 \%$ & 5 & $1 \%$ \\
\hline & 20-29years old & 151 & $80 \%$ & 616 & $69 \%$ & 174 & $16 \%$ \\
\hline & $30-39$ years old & 6 & $3 \%$ & 96 & $11 \%$ & 462 & $45 \%$ \\
\hline & 40years old or older & N/A & N/A & 18 & $2 \%$ & 397 & $38 \%$ \\
\hline
\end{tabular}

Note: The age expression in Choi et al. (2007a) has corrected as follows:

from "Under 19 years" to "19 years old or younger" and

from "Over 40 years" to "40 years old or older."

\section{Appendix 1. Survey Questionnaire to know how do mobile information services}

\section{improve quality of life}

(A.1) Overall, how do you feel about mobile information services (MIS) and the overall

Quality of Life?

\begin{tabular}{|l|l|}
\hline $\begin{array}{l}\text { Overall } \\
\text { Contribution }\end{array}$ & Items \\
\cline { 2 - 2 } & $\begin{array}{l}\text { 1) Using the MIS helps me make my life close to ideal. 2) Using the MDS improves the } \\
\text { general conditions of my life. 3) Using the MDS helps make my life more satisfying. 4) } \\
\text { Using the MDS helps me achieve important things in my life. }\end{array}$
\end{tabular}




\section{(A.2) Original individual life domains from Choi et al. (2007a)}

\begin{tabular}{|c|c|}
\hline $\begin{array}{l}\text { Original Life } \\
\text { Domains }\end{array}$ & Items \\
\hline Cultural & $\begin{array}{l}\text { 1) Purchasing movie or concert tickets over the MIS whenever I want, improves my } \\
\text { cultural life; 2) Making reservations for movies and concerts through the MIS while I } \\
\text { am out improves my cultural life; 3) Getting discount vouchers through the MIS before } \\
\text { going to a restaurant or cinema improves my cultural life; 4) Getting movie } \\
\text { information through the MIS on the street improves my cultural life; 5) When it's too } \\
\text { bothersome to go to the cinema, reserving tickets through the MIS improves my } \\
\text { cultural life. }\end{array}$ \\
\hline Leisure & $\begin{array}{l}\text { 1) Using the MIS to lift my spirits when I am gloomy improves my leisure life; 2) } \\
\text { Using the MIS to spend my spare time while I am out helps my leisure life; 3) MIS help } \\
\text { me to stay close with my personal interests, preferences and hobbies which improves } \\
\text { leisure life. }\end{array}$ \\
\hline Consumer & $\begin{array}{l}\text { 1) Frequently checking prices through the MIS while I am shopping improves my life } \\
\text { as a consumer; 2) Buying goods through the MIS instead of actually going out for } \\
\text { shopping improves my life as a consumer; 3) Searching for information on goods I } \\
\text { want to buy through the MIS, improves my life as a consumer; 4) Exchanging goods } \\
\text { over the MIS improves my life as a consumer. }\end{array}$ \\
\hline Financial & $\begin{array}{l}\text { 1) Using the MIS to send money electronically to another person when Iam away } \\
\text { improves my financial life; 2) Using the MIS to check my bank account improves my } \\
\text { financial life; 3) Using the MIS to buy and sell stocks/options instantly improves my } \\
\text { financial life; 4) Making reservations for trains with low commissions on the MIS } \\
\text { improves my financial life. }\end{array}$ \\
\hline Health & $\begin{array}{l}\text { 1) Recording health data daily through the MIS improves my health life; 2) Using the } \\
\text { MIS to take the medical advice when I can't use a PC improves my health life; } 3 \text { ) } \\
\text { Instead of going to the clinic or hospital, making an appointment by the MIS will } \\
\text { improve my health life. }\end{array}$ \\
\hline Safety & $\begin{array}{l}\text { 1) Using the MIS to search my location when I get lost at a strange place improves my } \\
\text { personal safety; 2) Searching for a safe route to my destination through the MIS late at } \\
\text { night improves my personal safety; 3) Being in contact with other people through the } \\
\text { MIS when I am alone improves my personal safety. }\end{array}$ \\
\hline Family & $\begin{array}{l}\text { 1) When I am concerned about my family members, searching for their current } \\
\text { location using the MIS improves my family life; } 2 \text { ) Getting in touch with my family } \\
\text { members through the MIS to relieve their worries improves my family life; 3) Sending } \\
\text { photos to my family over the MIS help my family life; 4) To be in constant contact with } \\
\text { my family when I am away improves my family life. }\end{array}$ \\
\hline Friend & $\begin{array}{l}\text { 1) Frequently sending photos to friends over the MIS improves my friendships; } 2 \text { ) } \\
\text { Frequently contacting friends through the MIS improves my friendships; } 3 \text { ) } \\
\text { Congratulating friends on their birthday over the MI improves my friendships. }\end{array}$ \\
\hline Self & $\begin{array}{l}\text { 1) Using the MIS to share my own photos with others improves my self-expression; 2) } \\
\text { Immediately upgrading to the latest services over the MIS increases my self-esteem. }\end{array}$ \\
\hline Community & $\begin{array}{l}\text { 1) Informing members of on-line community meeting dates over the MIS, improves } \\
\text { my community life; 2) Checking bulletin boards and e-mail from the on-line } \\
\text { community over the MIS improves my community life. }\end{array}$ \\
\hline Work & $\begin{array}{l}\text { 1) Searching for recruiting information through the MIS helps my work life; 2) } \\
\text { Discussing job-related issues with co-workers through the MIS helps my work life; 3) } \\
\text { Working through the MIS when I can't use a PC helps my work life }\end{array}$ \\
\hline
\end{tabular}


How do mobileinformation services improve quality of life? The case of Japanesestudents

\section{(A.3) Proposed individual life domains}

\begin{tabular}{|l|l|}
\hline Proposed Life Domains & Items \\
\hline Trustworthy & $\begin{array}{l}\text { 1) Having trust on the Internet services by MIS, improves my trustworthy life; } \\
\text { 2) Having trust on paying for the on-line shopping via MIS, will improves mu } \\
\text { trustworthy life; 3) Having trust on MIS while I am reading, entertaining and } \\
\text { getting information via internet, will improves my trustworthy life. }\end{array}$ \\
\hline Information & $\begin{array}{l}\text { 1) MIS helps me to get information of news, weather, maps, etc. when I need } \\
\text { which improves my information life; 2) I can search personal information } \\
\text { through MIS when I need which improves my personal life; 3) at anytime, } \\
\text { anywhere, be Searching information at anytime, anywhere by the MIS is fully } \\
\text { useful in order to improve my informational life }\end{array}$ \\
\hline Home-Healthcare & $\begin{array}{l}\text { 1) Using MIS to monitor blood pressure, glucose level, weight, food calorie etc. } \\
\text { by own self when I am home, improves my health life; 2) Using MIS in home for } \\
\text { diet control and medication agenda, etc., improves my health care }\end{array}$ \\
\hline Educational & $\begin{array}{l}\text { 1) Translate words through mobile dictionary anywhere anytime, improves my } \\
\text { educational life; 2) Reading newspapers, e-books through MIS, improves my } \\
\text { educational life; 3) to see the education program by the MIS when I cannot use } \\
\text { the PC, will improves my educational life. }\end{array}$ \\
\hline
\end{tabular}

